NASA CASE NO. LAR 14569-1

PRINT FIG. 1

\title{
NOTICE
}

The invention disclosed in this document resulted from research in aeronautical and space activities performed under programs of the National Aeronautics and Space Administration. The invention is owned by NASA and is, therefore, available for licensing in accordance with the NASA Patent Licensing Regulation 114 Code of Federal Regulations 1245.2).

To encourage commercial utilization of NASA-owned inventions, it is NASA policy to grant licenses to commercial concerns. Although NASA encourages nonexclusive licensing to promote competition and achieve the widest possible utilization, NASA will provide the necessary incentive to the licensee to achieve early practical application of the invention.

Address inquiries and all applications for license for this invention to NASA Patent Counsel, Langley Research Center, Code 143, Hampton, Virginia 23681-0001.

$\begin{array}{lll}\text { Serial No.: } & 08 / 238,044 \\ & 05 / 02 / 94 & \text { LaRC }\end{array}$

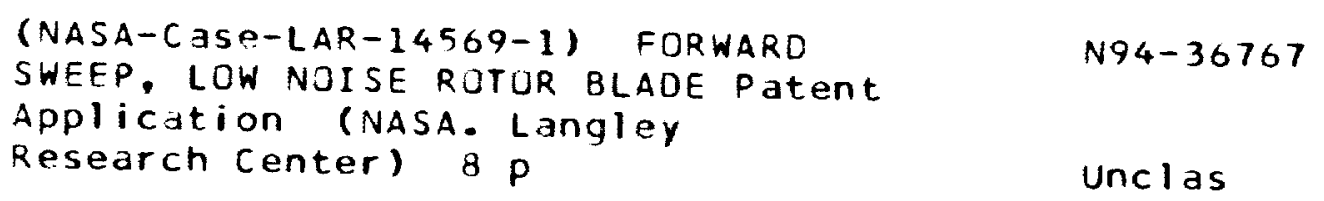




\section{FORWARD SWEEP, LOW NOISE ROTOR BLADE}

The present invention relates generally to a helicopter rotor blade and more particularly to a forward sweep, low noise rotor blade.

According to the present invention, a low noise rotor blade includes a straight inboard section, a forward-swept outboard section and an aft-swept section located between the straight inboard section and the forward-swept outboard section. The forwardswept outboard section measures between about $20 \%$ and $55 \%$ of the span of the rotor blade, and preferably measures $30 \%$ of the span of the rotor blade. The forwardsweep angle of the outboard section is between about $25^{\circ}$ and $45^{\circ}$, preferably, $35^{\circ}$. The inboard section measures between about $25 \%$ and $50 \%$ of the span of the rotor blade, and preferably measures $45 \%$ of the span of the rotor blade. The aft-swept section measures between about $15 \%$ and $40 \%$ of the span of the rotor blade, and preferably measures $25 \%$ of the span of the rotor blade. The aft-sweep angle of the aft-swept section is between about $15^{\circ}$ and $40^{\circ}$, preferably, $20^{\circ}$.

Novel aspects of the present invention include providing a rotor blade which reduces rotorcraft noise, in particular, blade-vortex interaction (BVI) noise. The present invention is passive in nature and is applicable to standard helicopters and tiltrotors.

\begin{tabular}{|c|c|}
\hline $\begin{array}{l}\text { Inventor: } \\
\text { Address: }\end{array}$ & $\begin{array}{l}\text { Thomas F. Brooks } \\
116 \text { Chisman Landing Road } \\
\text { Seaford, VA } 23696\end{array}$ \\
\hline $\begin{array}{l}\text { Employer: } \\
\text { Initial Evaluator: }\end{array}$ & $\begin{array}{l}\text { NASA LaRC } \\
\text { John S. Preisser }\end{array}$ \\
\hline $\begin{array}{l}\text { Serial No.: } \\
\text { Filed: }\end{array}$ & $\begin{array}{l}08 / 238,044 \\
5 / 02 / 94\end{array}$ \\
\hline
\end{tabular}


FORWARD SWEEP, LOW NOISE ROTOR BLADE

\section{Origin of the Invention}

5 The invention described herein was made by an employee of the United States Government and may be manufactured and used by or for the Government for governmental purposes without the payment of any royalties thereon or therefor.

10 Background of the Invention

\section{Technical Field of the Invention}

The present invention relates generally to a helicopter rotor blade and more particularly to a forward sweep, low noise rotor blade.

\section{Discussion of the Related Art}

Blade-vortex interaction (BVI) noise is one of the most objectionable types of helicopter noise. This impulsive blade-slap noise can be

20 particularly intense during low-speed landing approach and maneuvers. Over the years, a number of flight and model rotor tests have examined blade tip modification and other blade design changes to reduce this noise. Impulsive rotor noise is generally caused by localized aerodynamic events on the blade. At high advancing tip speeds, it is due to the 25 presence of transonic flow and associated shocks about the blade tip region. For this, blade tip speed and thickness effects are the most important parameters in defining the noise mechanism and thus its control. At lower speeds, where BVI noise dominates, the number of important parameters increases because the complexity of the rotor wake and its

30 embedded tip vortices becomes central to the problem. 
The important interactions on the advancing side of the rotor occur in the first quadrant (between azimuth angles of $\Psi=0$ to 90 deg.) where blades interact with tip vortices which were shed upstream. The resulting BVI noise is most strongly directed upstream on the advancing side below

5 the rotor. Strong BVI can also occur on the retreating side in the fourth quadrant, with noise directed below and downstream of the rotor. The local parameters which govern the intensity and directivity of BVI noise include the strength and core size of the tip vortex at the time of interaction, the interaction geometry (angles and "miss distances") of the

10 blade and vortex and the interaction Mach numbers. Of course, in turn, these parameters are determined by operational requirements, such as rotor thrust and flight conditions, and design parameters, such as rotor speed, number of blades, and blade section, planform, twist and tip shape.

One early BVI noise reduction approach taken was to modify the

15 blade tip vortex structure by tip shape design changes. While this approach was unsuccessful, general lessons learned through theoretical and experimental work were used to improve the blade designs. The newer design rotors were generally four-bladed with lower tip speed, thinner blade sections and swept tips. The effect was to decrease

20 thickness and high speed impulsive noises and, to a lesser extent, the BVI noise. Much of the progress in recent years has been in areas other than blade design. For example, flight operation procedures, such as changes in landing speed and descent rate for fixed glide slope approach, were found to reduce main rotor impulsive noise levels some 2 to $5 \mathrm{~dB}$. Rotor tip

25 speed reduction was used successfully on a light helicopter to reduce noise 3 to $4 \mathrm{~dB}$ by reducing rotor speed to 90 percent of standard rpm. Another method employed higher harmonic control $(\mathrm{HHC})$ of blade pitch to reduce BVI noise. Results have shown up to $6 \mathrm{~dB}$ BVI noise reduction depending on operating condition and control phase. Although the progress of these

30 studies is impressive, the operational and active control methods may be 
difficult to apply in practice. Also, for many rotorcraft, they may be less effective than passive blade and tip design changes.

It is accordingly an object of the present invention to provide a rotor blade which reduces rotorcraft noise.

It is a further object of the present invention to provide a rotor blade which reduces blade-vortex interaction (BVI) noise.

It is a further object of the present invention to provide a rotor blade which reduces $B V I$ noise in a passive manner.

It is a further object of the present invention to provide a rotor blade

10 which is applicable to standard helicopters and tiltrotors.

It is yet another object of the present invention to accomplish the foregoing objects in a simple manner.

Additional objects and advantages of the present invention are apparent from the drawing and specification that follow.

Summary of the Invention

A rotor blade is described which includes a straight inboard section, a forward-swept outboard section and an aft-swept section located

20 between the straight inboard section and the forward-swept outboard section. The forward-swept outboard section measures between about $20 \%$ and $55 \%$ of the span of the rotor blade, and preferably measures $30 \%$ of the span of the rotor blade. The forward-sweep angle of the outboard section is between about $25^{\circ}$ and $45^{\circ}$, preferably, $35^{\circ}$. The

25 inboard section measures between about $25 \%$ and $50 \%$ of the span of the rotor blade, and preferably measures $45 \%$ of the span of the rotor blade. The aft-swept section measures between about $15 \%$ and $40 \%$ of the span of the rotor blade, and preferably measures $25 \%$ of the span of the rotor blade. The aft-sweep angle of the aft-swept section is between about $15^{\circ}$ 30 and $40^{\circ}$, preferably, $20^{\circ}$. 


\section{Brief Description of the Drawing}

Fig. 1 is a top view of the rotor blade.

\section{Detailed Description of the Invention}

Figure 1 shows a rotor blade 10 having an inboard section 12, an aft-swept section 14 and an outboard forward-swept section 16. In a preferred embodiment, the inboard section 12 measures $45 \%$ of the span

10 of the blade 10 , the aft-swept section 14 measures $25 \%$ of the span of the blade 10 and the forward-swept section 16 measures $30 \%$ of the span of the blade 10 . The span of the blade 10 refers to the distance between the center of the rotor hub, upon which the blade is mounted, and the blade tip. The aft-swept section 14 is swept back at an angle 18 of $20^{\circ}$ from

15 the inboard section 12. The forward swept section 16 is swept forward at an angle 20 of $35^{\circ}$ from the inboard section 12 .

The actual dimensions of the straight inboard section 12 and the aftswept section 14 are dependent on aerodynamic and aeroelastic calculations after establishing the spanwise extent and sweep angle 20 of

20 the forward swept section 16. Aerodynamically, the design should set the location of the effective lift center to be close to the blade patch axis to minimize the control loads. The lift from the aft-swept section 14 and that portion of the forward-swept section 16 which is located aft of the $1 / 4$ chord projection line should nominally balance with the outboard forward

25 blade portion. Iterations with standard aeroelastic calculations are then required to establish structural design details.

The purpose of this rotor blade is to reduce the noise of rotorcraft, including both standard helicopters and advanced systems such as tiltrotors. The primary noise reduction feature is the forward sweep of the

30 planform over a large portion of the outer blade radius. The purpose of the 
aft-swept region is to provide a partial balance to pitching moments produced by the outboard forward-swept portion of the blade. The aftswept section permits both an aerodynamic and dynamic force balance for the blade along the $1 / 4$ chord line, and its projection, of the straight

5 inboard section. This allows hub-hinge forces and moments to remain within practical bounds. The aft section also provides the stabilizing blade forces and moments to counteract any forward-sweep-dependant instability which occurs during the blade's rotation. The noise source showing maximum noise reduction is BVI noise, as the forward-swept

10 section intercepts the advancing side tip vortices at skew angles to the blade rather than at near parallel angles, causing the BVI occurrences to lose much of their impulsive character, thus reducing noise. High speed thickness noise is also significantly reduced due to favorable surface thickness gradients for this planform. Compressive noise sources are

15 reduced and high advance ratio performance is improved over standard planforms due to the "forward-sweep" relief of the tip region compressive effect. The forward sweep maintains this benefit into the forward rotor quadrant on the advancing side and does not suffer from an unsweeping effect which may occur for swept back designs due to locally parallel

20 vortex orientations in that quadrant. Cabin vibration and loading noise are reduced due to a "load averaging" effect of the double sweep planform.

Although my invention has been illustrated and described with reference to the preferred embodiment thereof, I wish to have it understood that it is in no way limited to the details of such embodiment, 25 but is capable of numerous modifications for many mechanisms, and is capable of numerous modifications within the scope of the appended claims. 
FORWARD SWEEP, LOW NOISE ROTOR BLADE

\section{Abstract of the Disclosure}

A forward-swept, low-noise rotor blade includes an inboard section, an aft-swept section and a forward-swept outboard section. The rotor blade reduces the noise of rotorcraft, including both standard helicopters and advanced systems such as tiltrotors. The primary noise reduction feature is the forward sweep of the planform over a large portion of the

10 outer blade radius. The rotor blade also includes an aft-swept section. The purpose of the aft-swept region is to provide a partial balance to pitching moments produced by the outboard forward-swept portion of the blade. The noise source showing maximum noise reduction is blade-vortex interaction (BVI) noise. Also reduced are thickness, noise, high speed

15 impulsive noise, cabin vibration and loading noise. 

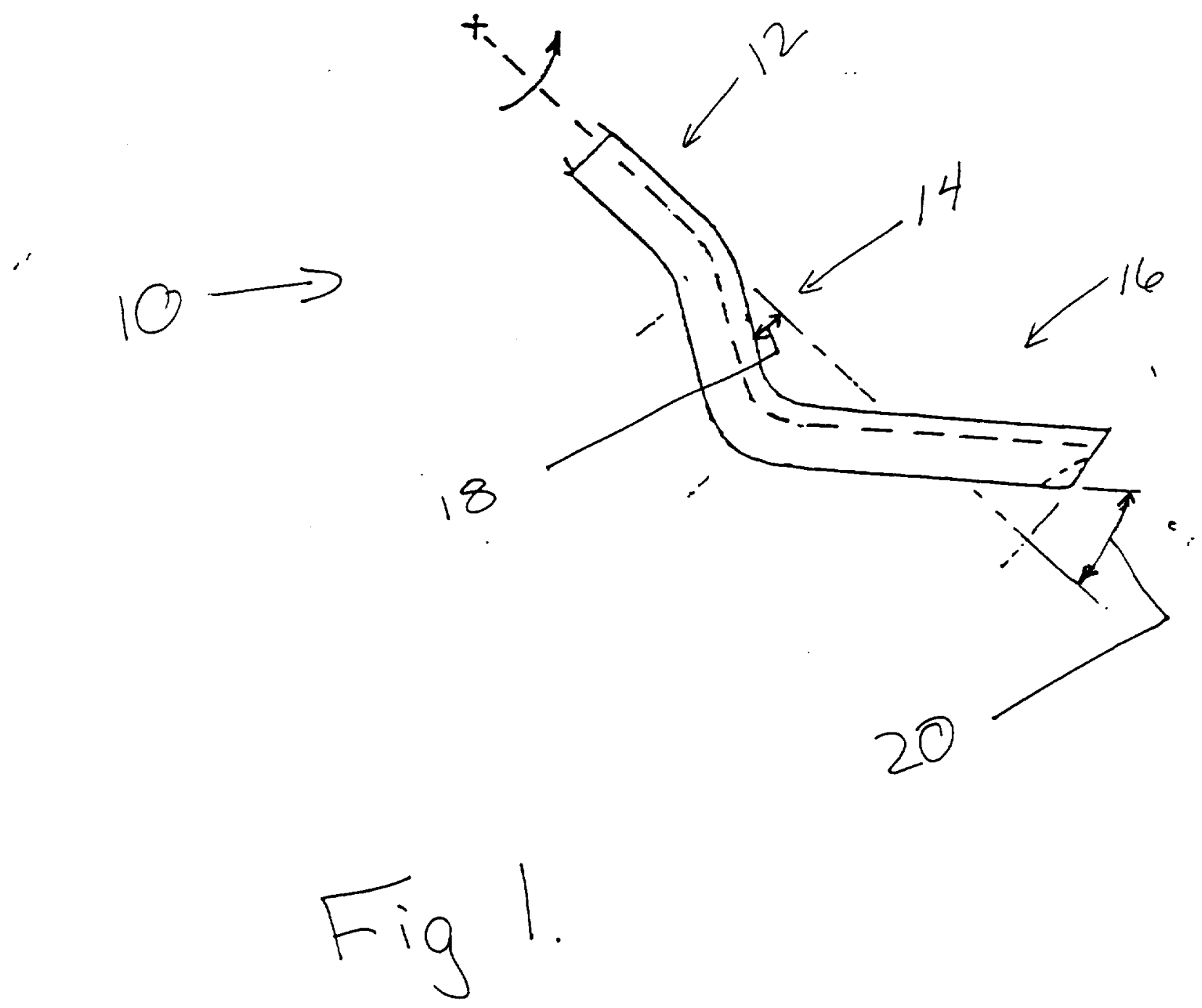